\title{
Comparison of two different screw trajectories in the treatment of oblique scaphoid fractures: A mechanical study on composite bone models
}

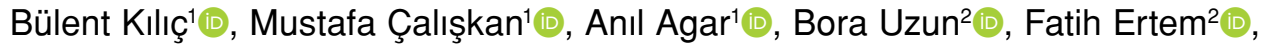 \\ Deniz Gülabi' ${ }^{1}$, Cemil Ertürk $^{1}{ }^{1}$ \\ ${ }^{1}$ Department of Orthopedics and Traumatology, University of Health Sciences, Istanbul Kanuni Sultan Suleyman Training and \\ Research Hospital, Istanbul, Turkey \\ ${ }^{2}$ Department of Biomechanics, Dokuz Eylül University, School of Medicine, Izmir, Turkey
}

The scaphoid bone is the most commonly fractured carpal bone and accounts for $15 \%$ of all wrist fractures. ${ }^{[1,2]}$ Transverse waist fractures (Herbert Type B2) are the most common type of unstable acute scaphoid fractures, followed by oblique scaphoid fractures (Herbert Type B1). ${ }^{[3]}$ Oblique scaphoid fractures are difficult to treat due to the shear forces generated by a more vertical pattern in the fracture line and the a high tendency toward development of a humpback deformity. ${ }^{[4]}$ Many studies have suggested that centrally placed screw fixation may be the most appropriate treatment option for all types of scaphoid bone fractures. ${ }^{[5-9]}$ On the other hand, we believe that similar stability may be achieved with perpendicular screw fixation (PSF) due to the increased contact

Received: March 08, 2021

Accepted: May 17, 2021

Published online: June 11, 2021

Correspondence: Bülent Kılıç, MD. SBÜ, Kanuni Sultan Süleyman Eğitim ve Araştırma Hastanesi, Ortopedi ve Travmatoloji Kliniği, 34303 Küçükçekmece, İstanbul, Türkiye.

E-mail: drbulentk@hotmail.com

Doi: $10.52312 /$ jdrs. 2021.15

Citation: Kılıç B, Çalışkan M, Agar A, Uzun B, Ertem F, Gülabi $D$, et al. Comparison of two different screw trajectories in the treatment of oblique scaphoid fractures: A mechanical study on composite bone models. Jt Dis Relat Surg 2021;32(2):377-382.

(อ2021 All right reserved by the Turkish Joint Diseases Foundation

This is an open access article under the terms of the Creative Commons Attribution-NonCommercial License, which permits use, distribution and reproduction in any medium, provided the original work is properly cited and is not used for commercial purposes (http://creativecommons.org/licenses/by-nc/4.0/).

\section{ABSTRACT}

Objectives: In this mechanical study, we aimed to compare two different screw trajectories in terms of durability against axial loads on oblique scaphoid fractures using composite bone models.

Materials and methods: Oblique osteotomies were made along the dorsal sulcus of 14 composite scaphoid bone models. Following this, all bone models were randomly classified. One group of bones were fixed with a screw placed perpendicular to the osteotomy line and the other group was fixed with a screw placed centrally down the long axis of the scaphoid bone. Each scaphoid bone model was positioned on a mechanical testing machine. Subsequently, axial loading tests were applied on each bone model to measure the amount of loading required to cause 2-mm displacement and failure on the osteotomy side and maximum displacement at the time of failure on scaphoid bone models.

Results: There was no statistically significant difference in load to 2-mm displacement and failure between the two groups $(p>0.05)$. Also, there was no statistically significant difference between the two groups in terms of maximum displacement seen on failure $(\mathrm{p}>0.05)$.

Conclusion: In our study, we found that the stability of the screws which laid perpendicular to the fracture line and parallel to the long axis of the scaphoid was the same in fixing oblique scaphoid fractures.

Keywords: Biomechanics, oblique scaphoid fractures, screw fixation, transverse fracture.

surface of fragments. Using the finite models, results similar to the behavior of materials in real-life environments are obtained in the in vivo settings. Results are expressed mathematically. ${ }^{[10]}$ Finite element study takes long time for planning. It is not an easy nonbiological test. ${ }^{[1]]}$ However, the Sawbones (Sawbones Inc., WA, USA) are good alternative to 
finite element studies. ${ }^{[12]}$ Finite element models (FEM) are very effective methods for testing the structure's behavior, when they are under the applied forces. They can be used to compare mechanical behavior of materials. ${ }^{[13]}$ The Sawbones are used as test materials and reliable for carpal bones. ${ }^{[14,15]}$ Therefore, we hypothesized that better mechanical results could be achieved with a screw laid perpendicular to the fracture line on oblique scaphoid fractures. To test our hypothesis, we designed a mechanical study on composite bone models aiming to compare these two different screw trajectories on oblique scaphoid fractures. In this mechanical study, we aimed to compare screw fixation perpendicular to the oblique osteotomy line with centrally placed screw fixation in terms of durability against axial loads and maximum displacement seen on composite scaphoid bone models.

\section{MATERIALS AND METHODS}

This mechanical study was conducted at University of Health Sciences, Istanbul Kanuni Sultan Suleyman Training and Research Hospital, Department of Orthopedics and Traumatology between June 2020 and February 2021. The study protocol was approved by Institutional Review Board (Date: 01.06.2020).

A total of 14 composite anatomic left scaphoid bone models (Sawbones Inc., WA, USA; Scaphoid, Foam Cortical Shell, Left SKU: 1010) were used in
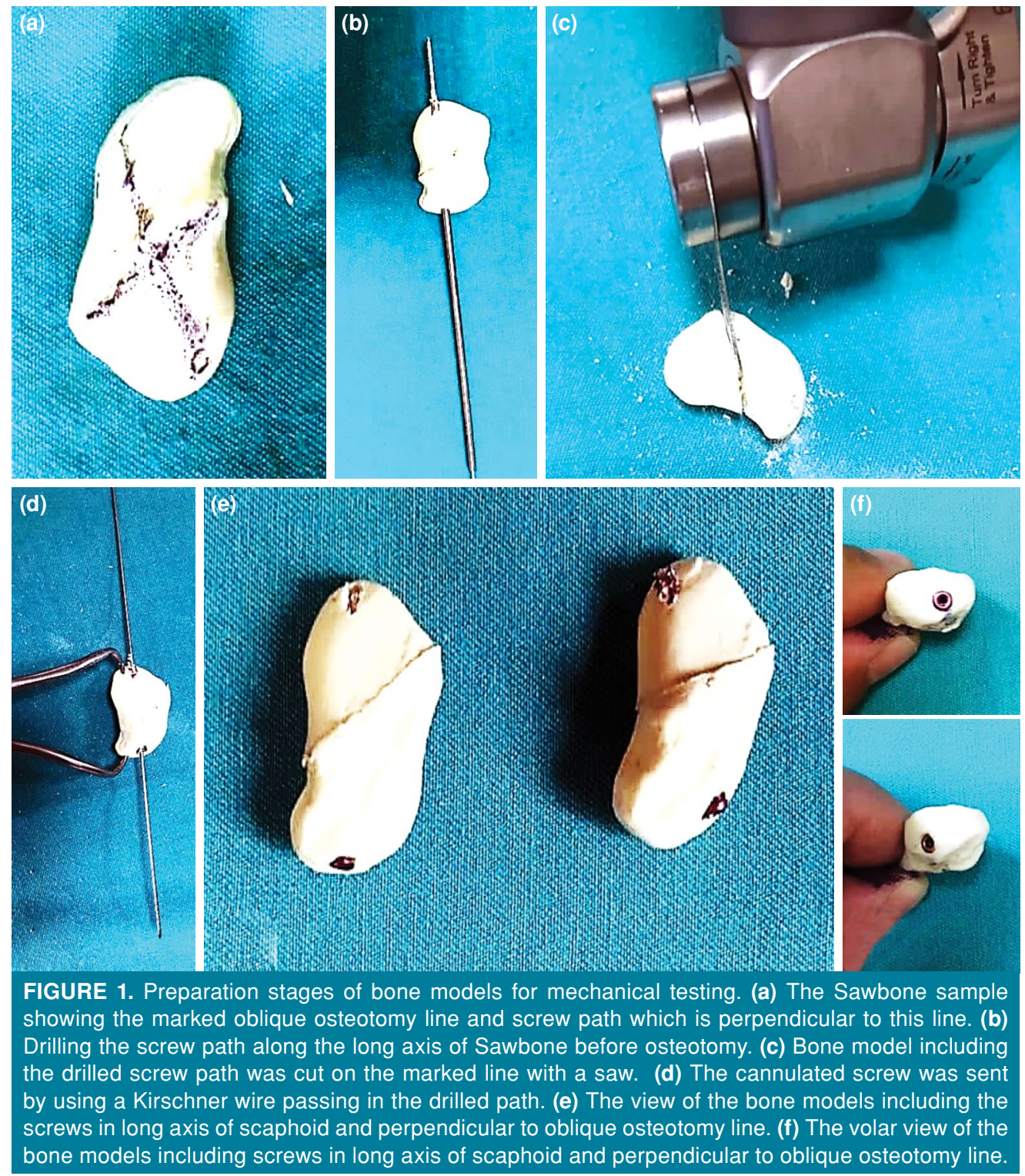


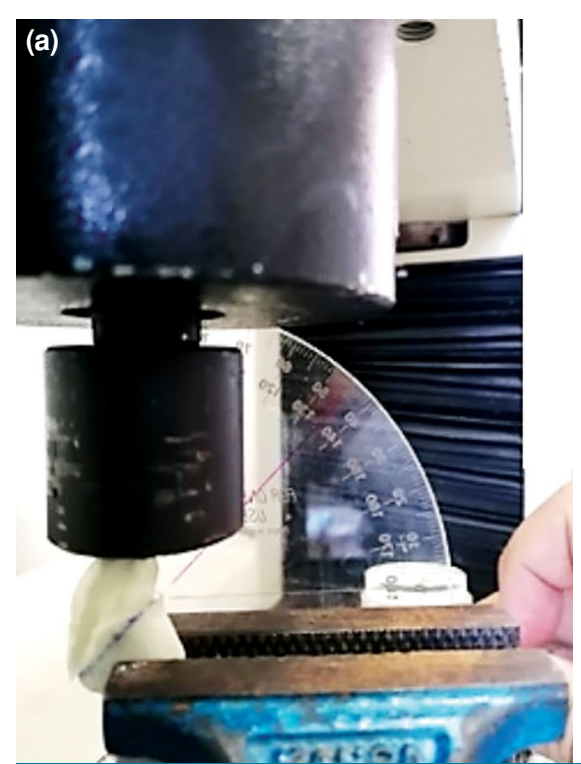

(b)

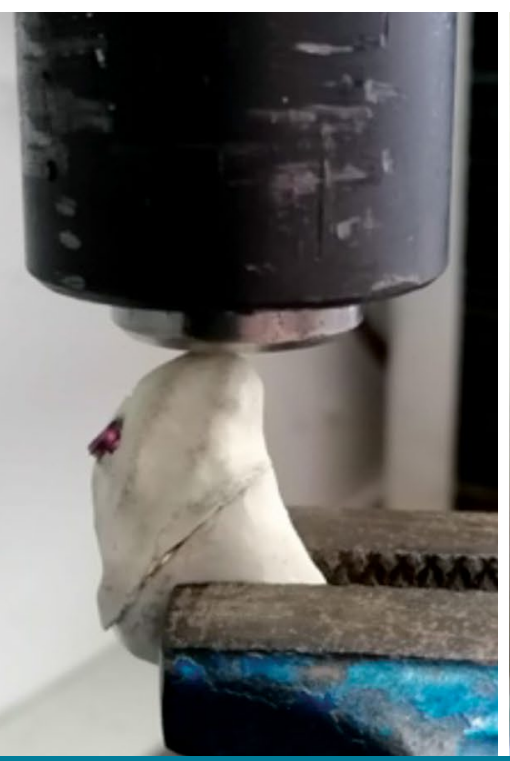

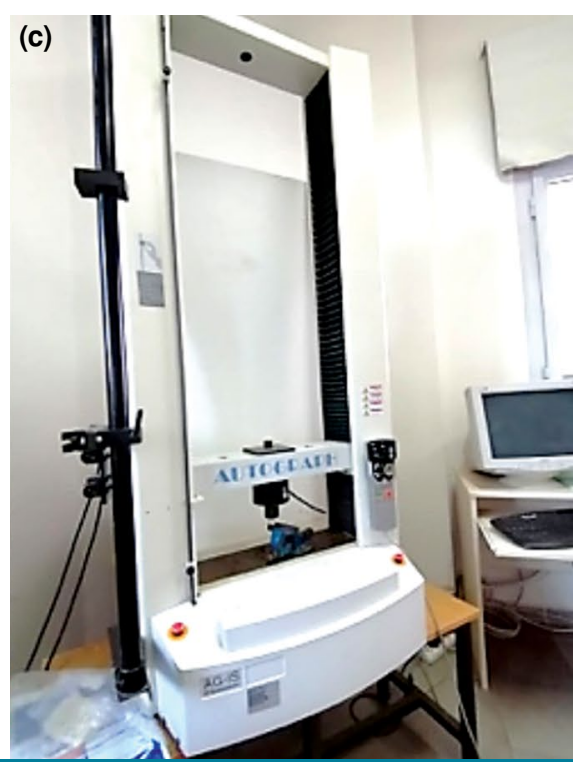

FIGURE 2. Positioning of bone model and application of mechanical test through the test machine (Shimadzu AG-I 10KN/Kyoto, Japan). (a) Positioning of bone model at an angle of 45 degrees with the horizontal plane in the test machine by using an angle meter. (b) Application of axial load to the sample by the test machine at the level of scaphoid distal pole point. (c) Appearance of testing machine.

this study. To obtain a Herbert Type B1 fracture on these bone models, an oblique osteotomy was applied with the same technique as described by Faucher et al. ${ }^{[4]}$ in their cadaveric study. With the aim of achieving a standardized reproducible osteotomy method, the proximal and distal poles were marked to determine the long axis of scaphoid bones. Subsequently, by drawing a line at an angle of 45 degrees to the long axis of scaphoid and roughly in line with the dorsal sulcus, the planned osteotomy line was created on all bone models (Figure 1a). Before making an oblique osteotomy, a guidewire was sent at a 90-degree angle to the planned osteotomy line on seven bone models and parallel to the long axis of the scaphoid bone for the other group. Screw paths were opened in both groups by drilling over the guidewires (Figure 1b). Then, the oblique osteotomy on the marked line was made by using a thin blade saw that has a $5-\mathrm{mm}$ width and 0.5-mm thickness (Figure 1c). After each osteotomy was created, the fragments were reduced anatomically and screwed. A length gauge was used to determine the appropriate screw length for each group. While the first group of oblique osteotomies were fixed with headless, fully-threaded 20-mm cannulated screws (TST Medical Devices, Istanbul, Turkey) laid perpendicular to the osteotomy line, the other group of osteotomies were fixed with headless, fully-threaded 24-mm cannulated screws (TST Medical Devices, Istanbul, Turkey) laid centrally to the long axis of scaphoid bone models (Figure 1d, e). Appropriate screw length was confirmed using visual inspection, and all screws were placed distal to proximal direction using a volar origin.

To simulate normal physiological loads which scaphoid bone encounters in a wrist held in the

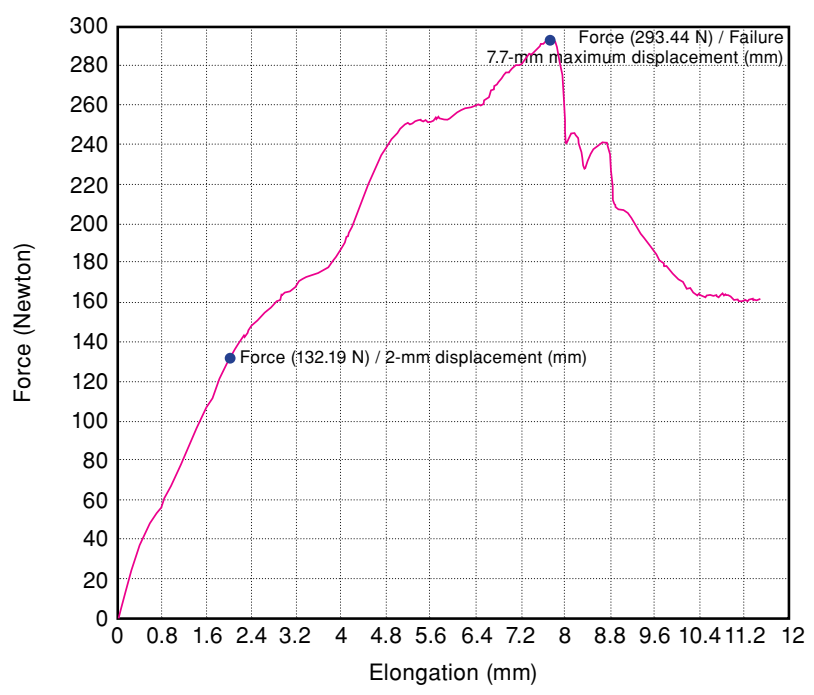

FIGURE 3. The graphic showing force and elongation results of Sample 3 of the perpendicular screw fixation group. Force/2-mm displacement $(\mathrm{mm})$ and force/maximum failure $(\mathrm{mm})$ results of the sample marked on the graphic. 


\section{TABLE I}

Results of the perpendicular screw fixation samples including the force required for 2-mm displacement and failure on the fracture site, maximum displacement amounts, and statistical results

\begin{tabular}{|c|c|c|c|c|c|c|c|c|c|}
\hline & \multicolumn{7}{|c|}{ Sample } & \multirow[b]{2}{*}{$\begin{array}{l}\text { Mean } \\
\text { value }\end{array}$} & \multirow[b]{2}{*}{ SD } \\
\hline & 1 & 2 & 3 & 4 & 5 & 6 & 7 & & \\
\hline Force/2-mm displacement $(\mathrm{N})$ & 294.38 & 194.38 & 132.19 & 272.81 & 302.5 & 192.34 & 150.93 & 219.93 & 69.55 \\
\hline Force/failure (N) & 319.38 & 325.47 & 293.44 & 427.97 & 349.22 & 310.15 & 237.03 & 323.24 & 57.96 \\
\hline Maximum displacement (mm) & 3.1 & 6 & 7.7 & 4.77 & 2.8 & 7.27 & 5.25 & 5.27 & 1.89 \\
\hline
\end{tabular}

neutral position, all bone models' fracture lines were positioned at a 45-degree angle to the horizontal plane of the testing machine. Thus, the delivery of dorsal to volar cantilever load was obtained on bone models. ${ }^{[4-9,16]}$ All samples were fixed to the holder of testing machine from their proximal poles (Figure 2a). Load was applied to the bone models perpendicular to the ground plane through a mechanical testing machine (Shimadzu AG-I 10KN/Kyoto, Japan) from the distal pole of the scaphoid (Figure $2 \mathrm{~b}$ ). The velocity of force applied by the machine is $20 \mathrm{~mm} / \mathrm{min}$. By increasing the load through the test machine, the amount of force causing 2-mm displacement and failure in the samples was calculated (Figure 3). The force resulting failure was defined as the maximum force that occurred before the anchoring structure was broken. In addition, the maximum displacement values at the failure point were measured by the test device.

\section{Statistical analysis}

Statistical analysis was performed using the IBM SPSS version 22.0 software (IBM Corp., Armonk, NY, USA). Descriptive data were expressed in mean \pm standard deviation (SD). The conformity of the variables to the normal distribution was evaluated using the Kolmogorov-Smirnov test and all variables were found to be normally distributed. The Student t-test was used for comparisons of data between the two groups. A $p$ value of $<0.05$ was considered statistically significant.

\section{RESULTS}

A total of seven composite scaphoid bone models were used in both groups. The results in each group were summarized in Tables I and II. The average force required to create 2-mm displacement was measured $219.93 \mathrm{~N}$ in the PSF group, while this value was 260.71 $\mathrm{N}$ in the long axis screw fixation (LASF) group. There was no statistically significant difference between the two groups in terms of force measurements required to create 2-mm displacement on the osteotomy site ( $>0.05)$.

The average force required to cause failure in the group in which screws were sent perpendicular to the fracture line was found to be $323.24 \mathrm{~N}$, while the value of this measurement was $342.50 \mathrm{~N}$ for centrally placed LASF group. There was no statistically significant difference between the two groups in terms of force required to cause failure $(\mathrm{p}>0.05)$.

In addition, there was no statistically significant difference between the two groups in terms of maximum displacement seen on failure $(p>0.05)$.

\section{TABLE II}

Results of long axis screw fixation samples including the force required for 2-mm displacement and failure on the fracture site, maximum displacement amounts, and statistical results

\begin{tabular}{|c|c|c|c|c|c|c|c|c|c|}
\hline & \multicolumn{7}{|c|}{ Sample } & \multirow[b]{2}{*}{$\begin{array}{l}\text { Mean } \\
\text { value }\end{array}$} & \multirow[b]{2}{*}{ SD } \\
\hline & 1 & 2 & 3 & 4 & 5 & 6 & 7 & & \\
\hline Force/2-mm displacement $(\mathrm{N})$ & 113.43 & 345.47 & 315.16 & 259.06 & 300.31 & 195.94 & 295.65 & 260.71 & 80.44 \\
\hline Force/failure (N) & 283.75 & 418.13 & 500.78 & 285.16 & 354.06 & 256.41 & 299.22 & 342.50 & 88.44 \\
\hline Maximum displacement (mm) & 7.56 & 2.65 & 3.6 & 3.78 & 4.32 & 2.5 & 2.05 & 3.78 & 1.85 \\
\hline
\end{tabular}




\begin{tabular}{|c|c|c|c|}
\hline $\begin{array}{r}\text { Statistical comparison o } \\
\text { force/2-mm }\end{array}$ & $\begin{array}{l}\text { TABLE III } \\
\text { etween perpendicular and long axi } \\
\text { ent }(\mathrm{N}) \text {, force/failure }(\mathrm{N}) \text { and maxin }\end{array}$ & $\begin{array}{l}\text { screw fixation group according } \\
\text { um displacement }(\mathrm{mm})\end{array}$ & \\
\hline & Perpendicular screw fixation group & Long axis screw fixation group & \\
\hline & Mean $\pm S D$ & Mean $\pm S D$ & $p$ \\
\hline Force/2-mm displacement (N) & $219.9 \pm 69.6$ & $260.7 \pm 80.4$ & 0.330 \\
\hline Force/failure $(\mathrm{N})$ & $323.2 \pm 58.0$ & $342.5 \pm 88.4$ & 0.638 \\
\hline Maximum displacement (mm) & $5.3 \pm 1.9$ & $3.8 \pm 1.9$ & 0.162 \\
\hline
\end{tabular}

While the maximum displacement was $5.27 \mathrm{~mm}$ in average for PSF group, this value was $3.78 \mathrm{~mm}$ for the LASF group (Table III).

\section{DISCUSSION}

There are three main findings of our study. First, there was no significant difference between the two groups in terms of force required for 2-mm displacement. Second, there was no significant difference between the two groups in terms of force required for failure. Third, there was no significant difference between the two groups in terms of maximum displacement seen on failure.

In our study, both groups provided a similar amount of resistance against axial force until 2-mm displacement. Comparing our results with a previous study performed by McCalister et al..$^{[5]}$ on cadaveric scaphoid bones with transverse fractures, it was observed that, in contrast to our findings, they achieved better results in the LASF group. The main reason for these differences between the two studies may be due to the dissimilar fracture types and material differences between cadaveric bones and sawbones. In the present study, we chose Sawbones, as they have the same size and density volume. Artificial bones have a similar elastic modulus, compressive strain values and stiffness, compared to the normal bone. ${ }^{[17]}$ In our study, no significant difference was found between the two groups in terms of resistance against axial force until failure point. Comparing our results with similar previous studies in terms of resistance against axial force until failure point, we observed the same results. Luria et al. ${ }^{[18,19]}$ showed in their studies that perpendicular fixation provided as much stability as LASF. Faucher et al. ${ }^{[4]}$ also found similar results to our findings in their cadaveric study.

In terms of maximum displacement seen at the failure point, we found no significant difference between the two groups. Our results are consistent with the previous study findings of Luria et al. ${ }^{[18]}$
In their study, the same length of screws with $21.5 \mathrm{~mm}$ was used for both fixation types and they achieved better results with the perpendicular fixation method, compared to LASF. In order to achieve accurate data, we first aimed to eliminate other factors such as bone quality, fracture geometry, fracture reduction and choice of implant affecting mechanical effectiveness of internal fixation, and we primarily focused on implant placement. Thus, we preferred to use composite bone models. Many recent studies have argued that composite bone models can mimic the properties of human bones and used as alternative testing media to human cadaveric bone. ${ }^{[20-22]}$ Furthermore, the similar oblique osteotomies were created on those composite bones and the same fixation materials were applied to the samples. Thus, we obtained reproducible testing materials.

Finite element analysis and preliminary clinical results in scaphoid nonunion by screw fixation were previously published in the literature, and correlation between the results were shown. ${ }^{[2]}$ In this study, we assumed that screwing in perpendicular position to the fracture would be most appropriate according to Arbeitsgemeinschaft für Osteosynthesefragen (AO) principles. Therefore, we believe that the screwing method should be in accordance with the AO principles, particularly in oblique fractures where short screwing is possible with volar and dorsal surgical approaches. It has been shown that perpendicular screwing is better for fracture treatment. ${ }^{[4]}$

Nonetheless, this study has several limitations. First, although composite bones are able to mimic normal human bones, it is difficult to simulate the in vivo conditions of human scaphoid. Additionally, only axial loading was applied to the samples due to the inability of applying torsional and bending forces of mechanical testing machine used in this study. However, scaphoid fractures are subjected 
to continuous shearing and bending forces during recovery. When we examined the test results in detail for each group, we found no significant correlation between the applied force and displacement. Finally, the number of composite bone samples could be more than seven to achieve more accurate data for this mechanical study.

In conclusion, according to our study findings, screw fixation perpendicular to the fracture line provided as much stability as LASF in terms of durability against axial loads on oblique scaphoid fracture models on composite bones. Future studies including more bone models and cyclic loads may yield more accurate results.

\section{Declaration of conflicting interests}

The authors declared no conflicts of interest with respect to the authorship and/or publication of this article.

\section{Funding}

The authors received no financial support for the research and/or authorship of this article.

\section{REFERENCES}

1. Hove LM. Epidemiology of scaphoid fractures in Bergen, Norway. Scand J Plast Reconstr Surg Hand Surg 1999;33:423-6.

2. Acar B, Köse Ö, Turan A, Katı YA, Güler F. Single versus double screw fixation for the treatment of scaphoid waist fractures: Finite element analysis and preliminary clinical results in scaphoid nonunion. Jt Dis Relat Surg 2020;31:73-80.

3. Tada K, Ikeda K, Okamoto S, Hachinota A, Yamamoto D, Tsuchiya H. Scaphoid fracture--overview and conservative treatment. Hand Surg 2015;20:204-9.

4. Faucher GK, Golden ML 3rd, Sweeney KR, Hutton WC, Jarrett CD. Comparison of screw trajectory on stability of oblique scaphoid fractures: A mechanical study. J Hand Surg Am 2014;39:430-5.

5. McCallister WV, Knight J, Kaliappan R, Trumble TE. Central placement of the screw in simulated fractures of the scaphoid waist: A biomechanical study. J Bone Joint Surg Am 2003;85:72-7.

6. Dodds SD, Panjabi MM, Slade JF 3rd. Screw fixation of scaphoid fractures: A biomechanical assessment of screw length and screw augmentation. J Hand Surg Am 2006;31:405-13.
7. Trumble TE, Gilbert M, Murray LW, Smith J, Rafijah G, McCallister WV. Displaced scaphoid fractures treated with open reduction and internal fixation with a cannulated screw. J Bone Joint Surg [Am] 2000;82:633-41.

8. Chang MA, Bishop AT, Moran SL, Shin AY. The outcomes and complications of 1,2-intercompartmental supraretinacular artery pedicled vascularized bone grafting of scaphoid nonunions. J Hand Surg Am 2006;31:387-96.

9. Panchal A, Kubiak EN, Keshner M, Fulkerson E, Paksima N. Comparison of fixation methods for scaphoid nonunions: A biomechanical model. Bull NYU Hosp Jt Dis 2007;65:271-5.

10. Zienkiewicz OC, editor. The Finite element method. 3rd ed. London: McGraw-Hill; 1977.

11. Taylor M, Prendergast PJ. Four decades of finite element analysis of orthopaedic devices: Where are we now and what are the opportunities? J Biomech 2015;48:767-78.

12. Muratlı SK, Uzun B, Çelik S. Comparison of five percutaneous pinning methods for unstable extra-articular distal radius fractures: A mechanical study using sawbones. Jt Dis Relat Surg 2021;32:51-8.

13. Richmond BG, Wright BW, Grosse I, Dechow PC, Ross CF, Spencer MA, et al. Finite element analysis in functional morphology. Anat Rec A Discov Mol Cell Evol Biol 2005;283:259-74.

14. Yashwant AV, Dilip S, Krishnaraj R, Ravi K. Does change in thread shape influence the pull out strength of mini implants? An in vitro study. J Clin Diagn Res 2017;11:ZC17-ZC20.

15. Sugathan HK, Kilpatrick M, Joyce TJ, Harrison JW. A biomechanical study on variation of compressive force along the Acutrak 2 screw. Injury 2012;43:205-8.

16. Green DP, editor. Green's Operative Hand Surgery. 6th. ed. Philadelphia: Elsevier/Churchill Livingstone, 2011.

17. Szivek JA, Thomas M, Benjamin JB. Characterization of a synthetic foam as a model for human cancellous bone. J Appl Biomater 1993;4:269-72.

18. Luria S, Lenart L, Lenart B, Peleg E, Kastelec M. Optimal fixation of oblique scaphoid fractures: A cadaver model. J Hand Surg Am 2012;37:1400-4.

19. Luria S, Hoch S, Liebergall M, Mosheiff R, Peleg E. Optimal fixation of acute scaphoid fractures: Finite element analysis. J Hand Surg Am 2010;35:1246-50.

20. Gokce V, Oflaz H, Dulgeroglu A, Bora A, Gunal I. Kirschner wire fixation for scaphoid fractures: An experimental study in synthetic bones. J Hand Surg Eur Vol 2011;36:325-8.

21. Hausmann JT, Mayr W, Unger E, Benesch T, Vécsei V, Gäbler C. Interfragmentary compression forces of scaphoid screws in a sawbone cylinder model. Injury 2007;38:763-8.

22. Melamed EA, Schon LC, Myerson MS, Parks BG. Two modifications of the Weil osteotomy: Analysis on sawbone models. Foot Ankle Int 2002;23:400-5. 